\title{
Using Subtitled Animated Cartoons and Textbook-based CDs to Test Elementary Students' English Listening and Reading Comprehension in a Cram School
}

\author{
Shu-Chin Su \\ English Department \\ The Danshui Campus of Aletheia University \\ E-mail: sshuchin@yahoo.com \\ Eleen Liang \\ Applied English Department \\ Southern Taiwan University \\ E-mail: eleenliang@yahoo.com
}

Received: 16-07-2014

doi:10.7575/aiac.ijalel.v.4n.1p.106
Accepted: 02-09-2014

Published: 01-01-2015

URL: http://dx.doi.org/10.7575/aiac.ijalel.v.4n.1p.106

\begin{abstract}
The present study is intended to investigate the students' preference for using subtitled animated cartoons and listening to CDs from the textbook to increase students' English learning on elementary cram school students. The purpose of this study is to compare and analyze students' preference on subtitled animated cartoons and listening to CDs in their listening and reading abilities. This study involved 60 participants from a cram school in Kaohsiung County, and divided into two groups, 34 for the experimental group and 26 for the control group. The researchers used authentic DVDs of animated cartoons as part of teaching materials for the experimental group of students. The results showed that using the subtitled animated cartoons for the scores of reading PART 1 (matching a description with a picture) was higher than using the text-based materials-CDs; gender plays no significant factor in determining pre-listening, prereading, post-listening, post-reading scores between two groups.
\end{abstract}

Keywords: animated cartoons, cram school

\section{Introduction}

Cram schools (private tutoring centers/ buxiban) play an important role in Taiwan because their function is to help students strengthen their learning in preparing for different exams (Yang, 1996). Tsai and Kuo (2008) stated "cram school is a special private school that offers additional after-school instruction to enhance students' achievement scores." (p. 356) Cram schools have a long history in some parts of East Asia, growing rapidly in the 1980s and 1990s. In Taiwan, a government census in 1998 lists 5536 tutoring centers and 1,891,096 students. Moreover, it is common for Taiwanese secondary students to attend more than one after-school cram school at a time (Bray, 2006). Cram schools are commonly found in Asian countries, such as Japan, Korea, China and Taiwan because these countries are deeply influenced by Confucianism, a majority of Taiwanese parents hope their children have the academic achievements, therefore, they send their children to cram schools for the intensive courses to enhance their academic competence. The parents spend extra tuition and students sacrifice their own time at cram school because the parents believe that cram schooling can advance their academic performance (Chung, 2013).

There are more studies need to be conducted to ascertain the effects of animated DVDs in both teaching and learning situations. Almost all of the studies were conducted within either colleges or elementary schools; none of the studies were focused on cram schools. Therefore, the present study can extend the research findings to younger students, such as elementary students in cram schools. The aim of this research is to point out the significant role of using animated cartoon in cram schools' success. Another aim is to make cram school teachers aware of what materials should be used in class to make their teaching more efficient. The study portrays that the effect of animated cartoons on elementary students' preference to learn English. This research intends to understand the asset of using types of authentic materialsanimated cartoons in English teaching.

\subsection{Research Question}

Due to the research purposes; the researchers started to conduct this study based on the ideas of using animated cartoons in teaching. The research is about how they respond to the question:

What is the students' preference of using animated cartoons and CDs from the textbook on testing elementary students' listening and reading comprehension? 


\subsection{Significance of the Study}

There were few researches conducted studies to investigate the preference of using animated cartoons and textbookbased CDs on cram school students' listening and reading comprehension. From the researchers' perspective, students are expected to be motivated by watching animated cartoons and their listening and reading comprehension are hypothesized to be improved. In addition, the result of this study might be useful for teachers in cram schools to use DVD animated cartoons as supplementary materials.

\section{Literature Review}

Listening comprehension development in EFL teaching are listed because using videos (DVDs) to improve learners' listening comprehension has been widely investigated in the past decade (Fast 2010; Garza 1991; Katchen 1996; Lee, 2009;MacMilliam, 1984). Authentic materials, implementation of using DVDs in class, advantages of showing animated cartoons with English subtitles, and empirical studies on using cartoons in teaching were introduced in this section. Many researchers have asserted that authentic materials have a great effect on learners' motivation (Fast, 2010; King, 2002; MacGillivray, 2005; Stempleski, 1987). Hence, it discussed authentic materials integrated with English teaching in listening. King (2002) emphasized that using DVDs provided learners sufficient listening input along with images. Teachers can always let the learners listen to the important scenes as many times as necessary. Zhuang (2007) conducted a research by merging English animated cartoons into teaching on an experimental group, and comparing it with the control group received story telling in Chinese and English to examine students'learning achievement. The research used a 35-item Likert-scale questionnaire and interview to investigate 68 elementary students' English learning motivation and achievement. The results revealed the experimental group's learning achievement to be better than the control group, especially in listening ability. For learning achievement in listening, it showed a more significant increase by the use of animated cartoons.

\subsection{Authentic Materials}

According to Richards,Platt, \&Platt (1998), authentic materials means "texts which are taken from newspapers, magazines, DVDs and tapes of natural speech taken from ordinary radio or television programs." (p. 34) 'Authentic materials" refer to "materials that are originally produced in a given language for a native-speaking audience of that language and not for learners of the language as a foreign language." (Garza, 1991, p. 241) Grellet (2004) emphasized the importance of using authentic texts as much as possible. "The authenticity idea develops naturally from a communicative orientation to language teaching." (Widdowson, 1996, p.67) Peacock (1997) added that authentic texts provided learners with the target language culture and brought pleasure into learning with motivation. King (2002) claimed that DVD feature films provide a wide series of pedagogical options and represent a productive resource of intrinsically motivating materials for learners. DVD teaching is considered one of the multimedia teachings. Unlike text-based teaching, watching animated cartoons created a fun learning environment.

According to the study by Zhuang (2007), the researcher summarized that multimedia material- authentic DVDs had been used as teaching materials in class from year 1980 to 2005. Stempleski (1987) further indicated that by using cartoons of materials, students found a fulfilling challenge and felt a great sense of satisfaction when they were able to understand concepts designed for native English speakers. Among all the various choices of DVDs, cartoons are the easiest to attract elementary institute students' attention and capture their imagination.

\subsection{Advantages of Showing Animated Cartoons with English Subtitles}

According to Fast (2010), by showing DVDs (digital video disc) with subtitles there appear to be two distinct advantages. First, learners benefited from viewing subtitles because they offered assurance that learners could check back on what they heard if they felt they need it. The second advantage was that learners felt more comfortable viewing the DVDs with subtitles and found them helpful for understanding. Cartoons contain a variety of contents with perspicuous plots which are easier for young learners to understand. Therefore, animated cartoons were proved more productive than movies for students because the socially significant dialogues influence the young minds (MacGillivray, 2005).

Most of the dialogues in the DVDs with English subtitles are adapted from real life stories, authentic and daily language (Leung \& Jenks, 2005). According to Flowerdrew and Miller (2005), using DVDs can improve students' listening ability and can benefit the listeners because they can show expression and sound at the same time to help students pay attention to the dialogues and understand the meaning. They enable students to be familiar with the social environment of the target language. Zhuang (2007) suggested that DVDs could be used as the effective media which enable learners to understand the culture context in a relaxing way of learning. Lee (2009) stated that animated cartoons increased students' motivation because of the sensory impact and the element of authenticity found in cartoons and resulting in students' improved attention span and stronger self-confidence. Based on the facts showed above, authentic animated DVDs with English title could be a helpful teaching tool for English teachers to use them in class and they could improve learners' English ability and increase learning motivation.

\subsection{Implementation of using DVDs in Class}

\subsubsection{Three Stages of Viewing DVDs}

Many scholars offered three stages of viewing DVDs (Flowerdrew\& Miller, 2005; King, 2002; Stempleski \& Tomalin, 1990; Zhuang, 2007) to engage in the pre-, while-, and post viewing activities to develop students' learning and to manipulate the DVDs more effectively in English teaching. The three stages of viewing DVDs are emerged in Table 1. 


Stages Procedures

Previewing 1. Talk about related topics of the videos to catch attention. Introduce the characters and the plots of the story (Stempleski\& Tomalin, 1990).

2.Preview the key words, phrases or idioms of the DVDs, and also explain the outline of the story to reduce the anxiety of learning (Zhuang, 2007).

3.Select dialogues which students may have problems to understand and practice them before watching the DVDs (King, 2002)

While viewing 1. Pay attention to students' reactions toward the DVDs.

2. If there are any important or represent scenes, teachers can stop or rewind the DVDs and explain it right away (Zhuang, 2007).

Post viewing 1. Teachers can use vocabulary, phrases or sentence patterns to design generic worksheets which give students more chance to practice what they learn from the DVDs (Zhuang, 2007).

2. After a video has been viewed, trouble-shooting proved helpful in terms of clarifying confusing scenes and enhancing students' overall comprehension (Flowerdrew\& Miller, 2005).

3. After watching the DVDs, a group discussion could also give students a chance to talk about the story, at the same time review the vocabulary they learned (Stempleski \& Tomalin, 1990).

Flowerdrew and Miller (2005) suggested that when students view DVDs; teachers need to pay attention to some possible problems concerning content. Figure 1 showed what steps that teachers should be aware of before and after viewing DVDs.

2.3.2 The Steps of Viewing DVDs

Choosing appropriate DVDs; avoid subjects such as sex, violence and slangs.

\begin{tabular}{|l|l|}
\hline Before viewing & \\
\hline After viewing & $\begin{array}{l}\text { Previewing the DVDs; pay attention to the section that learners may have } \\
\text { difficulty understanding. }\end{array}$ \\
\hline \hline $\begin{array}{l}\text { Bake generic worksheets; focus on the vocabulary or grammar that teachers } \\
\text { put emphasis on. } \\
\text { purpose of viewing the DVDs. }\end{array}$ & $\begin{array}{l}\text { Encourage learners to contract their extensive listening skills by using group } \\
\text { discussions. }\end{array}$ \\
\hline $\begin{array}{l}\text { Consider the follow-up activities and tasks to exploit the materials which are } \\
\text { also an important issue. }\end{array}$
\end{tabular}

Figure 1. Teachers should be aware of before and after viewing DVDs. Adapted from "Second language listening: Theory and practice," by Flowerdrew, J. \& Miller, L. (2005), p.173.

\subsection{Empirical Studies on Using Cartoon in Teaching}

Several researchers have conducted similar researches to this study and the results are as follow: Luo (2003) had conducted the research on college freshmen for one semester and the findings showed that using DVD films not only reduced learners' anxiety but also motivated them to learn English. Moreover, it also enhanced the students' listening. Lee (2009) used feature films as instructional tools on Applied English major students which lasted for one semester, and the result presented that the feature films assisted the learners in improving listening and speaking. From the results of other researchers had completed from 2003, they presented the same finding: using films, cartoons or movies could improve learners' listening in all levels. Zhuang (2007) used English cartoon movies into teaching on fifth graders in elementary school. The findings were: 1.the experimental group's learning achievement with cartoon movies was better than the control group's. 2. Students in the experimental group thought the cartoon movies benefited their listening. In addition, Filiz (2009) used a case study to propose several ways to find out the effectiveness of using cartoons on learning. The findings of the study indicated that cartoons are as effective in remedying students' misconceptions. The researcher also indicated that cartoons promoting students' understanding and developing children's scientific ideas.

\section{Method}

This research is designed to examine students' preference by using animated cartoons and textbook-based CDs as supplementary materials for elementary students in cram schools. The process of the experimental course consists of pre- and post-tests. Experimental research was applied in this study to examine the effect of listening and reading comprehension by using animated cartoons. The control group also had pre- and post-tests, this group used the same 
textbook without animated cartoons, but listened to CDs from textbook. This research design included the participants, instruments, procedure and data analysis. Animated cartoons were used as supplementary material in this study.

Table 2. The Experimental Design

Pre-test $\quad$ Treatment $\quad$ Post-test

Experimental group

Control group
Test A Same textbook + Animated cartoons

Test A Same textbook+ without animated

(listening songs from the textbook)
Test B

Test B

Note. Adapted from Lynch,B. K. (1996). Language program evaluation: Theory and practice, p.71. New York, the USA: Cambridge University Press.

\subsection{Pilot Study}

The pilot study was considered to be a guidance to adjust the action taken in the formal study and also gave the researcher specific directions to follow. The data collected from the study was analyzed mainly using Mann-Whitney U Test and paired-samples $t$-test to test the confidence interval (CI). A pilot study was conducted for three months and the framework of the pilot study was similar to the present research. The aim was to detect any unexpected practical problems, and to collect data to test the reliability of the instruments. The participants originally consisted of 21 students (13 boys, 8 girls) and the average age of these participants was 10 years old. However, during the experiment, four students from the experimental group did not complete the course. One of the four participants transferred to another class, and three students did not continue to study in the cram school. Therefore, in the pilot study, there were a total of 17 participants, 8 participants in the experimental group and 9 participants in the control group that completed the whole process and were from different classes in the same cram school.

A Cronbach's alpha coefficient of .921 on motivation, .901 on grade, and .840 on attitude evaluation were obtained which suggested the survey proved to be consistent and the questionnaire possess a high reliability. In other words, it was an appropriate instrument to analyze the data. The significance level was set to be 0.1 due to the fact that small sizes used in the pilot study. The results showed that the time of learning English between the experimental group and the control group had significant difference $(p$-value $=.059)$. Thus, the results showed that the time of learning English affected the test result which means the longer the students learn English, the better performance from the participants present in the tests. As for motivation, it showed the significant difference $(p=.093)$ between the experimental group and the control group. This implied that textbook with animated cartoons teaching increased the motivation of learning more than textbook with songs teaching. When comparing the effects of using materials between using cartoons and text CDs songs from listening and reading, the results showed that for listening, it showed a slight difference preferring the use of cartoons $(p=.143)$ than text CDs, and as for reading, it showed no significant difference $(p=.643)$

The output showed a Pearson's $r$ correlation between the reported year of learning English and the score in listening found the correlation to be significant $(p=.031)$. The correlation between time of learning English and scores on reading was $0.452(p=.068)$. It meant that the correlation did not exist. The result of Paired-Samples t-test showed that $90 \%$ confidence interval (CI) of post-test score minus pre-test score of control group [CI: 5.40, 23.04] for listening, [CI: $14.46,6.68]$ for reading. In experimental group [CI: -9.12, 19.12] for listening, [CI: -6.26, 10.26] for reading. Therefore, the result of the pilot study indicated a significant improvement in listening but insignificant in reading.

3.2 Present Study

The researcher selected students that had at least two years English learning experience, ensuring that they would have minimal problem understand the dialogues but at the same time presenting a challenge which would therefore provide realistic results, consequently the worksheets provided would highlight a greater variance and enable the researcher to obtain more accurate results.

\subsection{Participants}

The participants were 60 students ( 23 boys, 37 girls) and the average age of these participants in the experimental group (34 students) was 10 years old and 11 years old in the control group (26 students).

\subsection{Instruments}

The participants took ILTEA (International Learning, Teaching and Evaluation Agency) with the Starter Level of Young Speakers' listening and reading tests as pre- and post-test. Since 1998, ILTEA has been the most popular English test for young speakers of other languages in Taiwan, Hong Kong, and China. ILTEA also meets the international standards which adopts by the United Nations Member States and CEFR standard of education recognized by the Ministry of the European Union (ILTEA Education Group, 2012). The organization is recognized as reliable for its professionalism, authenticity, and organizational credibility in the world. The pre- and post-tests were employed by ILTEA and consisted a separate listening and reading component for a total score of 100 points.

The listening testing consists of four parts and five questions for each: 1. connecting conversational items with pictures, 2. writing down names and numbers that are heard, 3.choosing pictures to go with the dialogue, and 4. choosing objects to go with the dialogue. The reading testing consists of five parts and five questions for each: 1. matching a description with a picture, 2. answering 'yes' or 'no' to the accuracy of descriptions supplied by the teacher, 3. unscrambling words, 4. filling in the blanks, and 5. answering questions with a single word (ILTEA Education Group, 2012).

This study used Cronbach's alpha to test the consistency. When Cronbach's $\alpha>.6$, it means the questionnaire has a high consistency. For the formal study, the Cronbach's alpha coefficient were .803 on motivation questionnaire, .826 on pre- 
listening, .817 on pre-reading, and .720 on attitude evaluation and considered as consistent and possessed a high level of reliability. In other words, it is an appropriate instrument to analyze the data.

3.5 Target DVDs (Cartoons)

An animated cartoon was used as supplementary material in the pilot study. The animated cartoon, "UP", an instructional DVD published by Disney/Pixar in 1995, was selected. "UP" is a comedy adventure film centered on an elderly widower named Carl Fredricksen and an earnest young wilderness explorer named Russell who flies to South America in a house suspended by helium balloons. The cartoons, "The Wrong Trousers" of the Wallace and Gromit series and "Madagascar: Escape 2 Africa" were chosen for the formal study. "The Wrong Trousers" is a 1993animated film directed by Nick Park at Aardman Animations, featuring his main characters Wallace and Gromit. All the characters are made from molded plasticine modeling clay on metal armatures, and filmed with stop motionclay animation. "Madagascar: Escape 2 Africa" is a 2008 animated film written by Etan Cohen, and directed by Eric Darnell and Tom McGrath. This sequel to the 2005 film Madagascar continues the adventures of Alex the Lion, Marty the Zebra, Melman the Giraffe, and Gloria the Hippo. It won the 2009 Kids' Choice Award for Favorite Animated Cartoon. To adapt to the elementary level learners in language institutions, DVD animated cartoons with English subtitles were chosen for this study.

\subsection{Procedures}

First, it was carried out in the class for one hour per week-thirty minutes were needed for going through the worksheets, introduction of the key words, phrases, and sentence patterns in the movie. And then, another thirty minutes for watching the cartoons and filling answers in the worksheets. In the next class, teachers discussed the worksheets (see Appendix I \& II ) which were designed for each part of the DVDs with the class. The worksheets included sections of vocabulary, sentences/phrases, fill in the blanks, multiple choices, and Q \& A and so on. The worksheets played a very important role for using animated cartoon in a cram school because the strategies used in the worksheets were the purpose of testing students' listening and reading comprehension. This study included one week of pre-test, 3 months to conduct the experiment, and one week post-test and surveys on both the control and experimental groups. The participants undertook ILTEA (International Learning, Teaching and Evaluation Agency) with the Starter Level of Young Speakers' listening and reading tests as pre- and post-test. After completing pre-tests, the experimental group received a total of 16 hours in 3 months of viewing DVDs a long side the traditional grammatical lessons while the control group maintains the regular curriculum with a total of 16 hours in 3 months of listening to CDs/songs from the textbook.

\subsection{Data Analysis}

The quantitative data included the students' results of pre-test and post-test by the computer software SPSS (Statistical Package for the Social Science). To answer the research questions, Mann-Whitney U Test is to conduct and evaluate the preference of animated cartoons on students' listening and reading comprehension. The participants' score of pre- and post-tests before and after the treatment evaluated whether there are significant differences of students' test performances by using animated cartoons as supplementary material.

\section{Results and Discussion}

\subsection{Results of the Analysis}

The main purpose of this study was to describe and classify the students' preference of merging animated cartoons for the purpose of language learning in English based cram schools. The results and findings of the tests are followed by commentary and discussion. In the study, the significance level is set to be 0.005 . From the statistic result showed in Table 3, the students had varying differences in age $(p<.001 *)$, it presented that the average age in the control group $(m e a n=11)$ was older than the experimental group (mean=10). Furthermore, the control group had much higher pre-test listening scores (mean $=81.5 ; p<.001 *)$; the students in the control group also had higher score on pre-test reading score (mean=61.46) than the experimental group (mean=53.91). It means the students in the control group are older and have better English proficiency in listening and reading skills before the experiment starts.

Table 3. Description Statistic of Formal Study

\begin{tabular}{lcccccccccccc}
\hline & \multicolumn{4}{c}{ Experimental Group } & \multicolumn{4}{c}{ Control Group } \\
\hline & Min & Max & Mean & Medium & SD & Min & Max & Mean & Medium & SD & $p$-value \\
\hline Age & 9 & 12 & 10.26 & 10 & 0.9 & 9 & 12 & 11.42 & 11.5 & 0.7 & $<.001 *$ \\
Years of learning English & 2 & 6 & 3.71 & 4 & 1.12 & 2 & 6 & 4.42 & 4 & 1.42 & .06 \\
Pre-test listening score & 19 & 90 & $\mathbf{6 5 . 8 5}$ & 69.5 & 18.15 & 54 & 98 & $\mathbf{8 1 . 5}$ & 84 & 8.66 & $<.001 *$ \\
Pre-test reading score & 12 & 84 & $\mathbf{5 3 . 9 1}$ & 57 & 18.17 & 16 & 92 & $\mathbf{6 1 . 4 6}$ & 63 & 17.39 & .11 \\
Post-test listening score & 30 & 95 & 74.56 & 78.5 & 16.94 & 53 & 98 & 83.19 & 86.5 & 11.7 & - \\
Post- test reading score & 4 & 87 & 57.71 & 63 & 20.28 & 23 & 83 & 61.88 & 67 & 17.28 & - \\
\hline
\end{tabular}

Using Mann-Whitney U Test $(* p<.005)$

The statistical results in Table 4 showed that gender plays no significant differences in determining pre-listening and reading, post-listening and reading scores; therefore, it could be assumed that gender was not a variable in this study. 
Table 4. Statistics of the Gender Effect

\begin{tabular}{ccccccccccccc}
\multicolumn{1}{c}{ Sex } & \multicolumn{1}{c}{ Boys } & \multicolumn{1}{c}{ Girls } \\
\hline \multicolumn{1}{c}{ Mge } & Minimum & Maximum & Mean & Medium & SD & Minimum & Maximum & Mean & Medium & SD & $p$-valu \\
\hline Years of learning English & 9 & 12 & 10.86 & 11 & 0.87 & 9 & 12 & 10.7 & 11 & 1.08 & .657 \\
\hline Pre-listening & 2 & 6 & 4.13 & 4 & 1.14 & 2 & 6 & 3.95 & 4 & 1.39 & .473 \\
\hline Pre-reading & 20 & 98 & 72.83 & 79 & 15.89 & 19 & 90 & 72.51 & 80 & 17.32 & .652 \\
\hline Post-listening & 24 & 87 & 57.87 & 60 & 16.4 & 12 & 92 & 56.76 & 59 & 19.26 & .885 \\
\hline Post-reading & 48 & 98 & 80.04 & 85 & 14.3 & 30 & 95 & 77.22 & 83 & 16.14 & .843 \\
\hline
\end{tabular}

Using Mann-Whitney U Test

In Table 5, there was a significant result $(p=\mathbf{. 0 0 1 *})$ found in PART1 of the reading (post-reading test). The average score of the students who prefer watching cartoons in post reading (PART 1) was $\mathbf{2 . 0 8}$ (higher), but the average score of the students who prefer listening textbook-based CDs was -3.33 (lower). According to Table 3 the students in the control group are older and have better English proficiency in listening and reading skills before the experiment starts. However, the result in Table 5 indicated that after watching cartoon for three months, the experimental group of students had the higher score on post reading which means the students' reading comprehension in the experimental group is greater than the control group after three months. The result might conclude that using animated cartoons in cram school enhance students' reading ability on matching a description with a picture.

Table 5. Statistic Results of Preferring Listen to CDs(textbook) and Watching Animated Cartoons inEach Part

\begin{tabular}{|c|c|c|c|c|c|c|c|c|c|c|c|}
\hline & \multicolumn{4}{|c|}{ Prefer textbook (Listen to CDs) } & \multirow[b]{2}{*}{ SD } & \multicolumn{4}{|c|}{ Prefer Cartoons } & \multirow[b]{2}{*}{ SD } & \multirow[t]{2}{*}{$p$-value ${ }^{\mathrm{a}}$} \\
\hline & Minimum & Maximum & Mean & Medium & & Minimum & Maximum & Mean & Medium & & \\
\hline \multicolumn{12}{|l|}{ Pre-listening } \\
\hline PART1 & 0 & 20 & 7.92 & 5 & 7.82 & 0 & 25 & 10.83 & 10 & 6.71 & .218 \\
\hline PART2 & 5 & 25 & 18.08 & 19.5 & 4.85 & 5 & 25 & 18.77 & 19 & 3.92 & .917 \\
\hline PART3 & 10 & 25 & 22.91 & 25 & 4.50 & 0 & 25 & 23.33 & 25 & 4.42 & .728 \\
\hline PART4 & 5 & 25 & 18.33 & 20 & 6.15 & 0 & 25 & 21.04 & 25 & 5.92 & .07 \\
\hline \multicolumn{12}{|l|}{ Pre-reading } \\
\hline PART1 & 8 & 20 & 16 & 16 & 2.95 & 0 & 16 & 13.58 & 16 & 3.38 & .008 \\
\hline PART2 & 4 & 20 & 14.33 & 16 & 5.25 & 4 & 20 & 13.81 & 16 & 4.47 & .581 \\
\hline PART3 & 0 & 20 & 12.33 & 16 & 6.26 & 0 & 20 & 11.75 & 12 & 4.91 & .422 \\
\hline PART4 & 0 & 16 & 8.75 & 11 & 6.06 & 0 & 20 & 9.48 & 11 & 5.42 & .716 \\
\hline \multicolumn{12}{|l|}{ Post-listening } \\
\hline PART1 & 0 & 15 & 9.17 & 10 & 5.15 & -15 & 25 & 8.85 & 10 & 7.38 & .909 \\
\hline PART2 & -20 & 15 & -3.33 & -2.5 & 8.21 & -15 & 10 & -1.04 & -1 & 5.58 & .303 \\
\hline PART3 & -10 & 5 & -2.91 & -5 & 4.98 & -10 & 10 & -2.19 & 0 & 4.11 & .566 \\
\hline PART4 & -10 & 15 & 0 & 0 & 7.39 & -15 & 20 & 0.73 & 0 & 7.15 & .602 \\
\hline Post-pre & -40 & 40 & 2.92 & 4 & 18.36 & -21 & 49 & 6.35 & 6.5 & 13.82 & .488 \\
\hline \multicolumn{12}{|l|}{ Post-reading } \\
\hline PART1 & -16 & 4 & -3.33 & -4 & 5.07 & -16 & 20 & 2.08 & 4 & 5.95 & $.001 *$ \\
\hline PART2 & -4 & 12 & 1.67 & 0 & 4.96 & -8 & 12 & 2.10 & 4 & 4.57 & .582 \\
\hline PART3 & -12 & 12 & 0.33 & 0 & 6.02 & -8 & 12 & -0.08 & 0 & 4.85 & .76 \\
\hline PART4 & -5 & 8 & 0.25 & 0 & 4.05 & -12 & 12 & -0.69 & -1 & 4.96 & .434 \\
\hline PART5 & -8 & 7 & -0.58 & 0 & 4.52 & -8 & 11 & -0.08 & 0 & 4.47 & .889 \\
\hline Post-pre & -25 & 13 & -1.67 & 3 & 12.17 & -23 & 29 & 3.33 & 4.5 & 12.06 & .271 \\
\hline
\end{tabular}

* Using Mann-Whitney U Test 


\section{Conclusion}

The finding indicates that gender factor has no significant effect on age, years of learning English, students' listening comprehension, and reading comprehension of using animated cartoons in cram school. In addition, from the test results, the students in the control group had better English proficiency at the beginning, however, after three months of experiment, the students in the experimental group had better performance in reading (PART 1) that was an evidence to show that students were be able to do better on matching description with pictures in reading comprehension. The main reason might be that animated cartoons are very interesting and attractive for young learners. Therefore, to enhance students' reading by watching cartoons was so effective. It is a question for teachers to use or not to use the authentic materials such as animated cartoons in their classes. As for this study, it lasted for three months for experiment and two months of collecting data; it can be concluded that using DVD animated cartoons as supplemental material created a motivating environment and also helped students improve their reading. Actually, learning individual vocabulary words from the worksheet could also assist students' reading abilities. It is not just play cartoons in classroom, a proper designed worksheets is important for using animated cartoons in cram school. In summary, this evidence could be concluded that using DVD animated cartoons as teaching material created a motivating environment compares with listening to CDs from the textbooks. From the results shown, it might be concluded that compared to traditional teaching methods, through watching animated cartoons might benefit students in reading, and gender of the students was not a considerable factor. If teachers want to increase students' reading ability, choosing subtitled animated cartoons could be considered an alternative teaching method and it is the activity students can relax and enjoy.

\section{References}

Alderson, J. C. (2000). Assessing reading. Cambridge, United Kingdom: The University Press of the University of Cambridge.

Bray, M. (2006). Private supplementary tutoring: comparative perspectives on patterns and implications. New Review of Academic Librarianship,36(4), 515-530. doi:10.1080/03057920601024974.

Brennam, M., \& Woodbury Miller, J. (1982). Making an English language teaching videotape. ELT Journal, 36(3), 169-174.

Brown, H. D. (2007). Teaching by principles. San Francisco, the USA: Longman.

Chang, C. K. (2005) • The Exploration of the Situation of Attending Cram Schools for the Elementary School Students and their Parents 'Behavior of Decision - Sampling the Situation of Tainan City. Unpublished master's thesis, National Tainan University of Tainan, Tainan, Taiwan.

Chung, I. F. (2013). Crammed to Learn English: What are Learners' Motivation and Approach? The Asian Pacific Education Researcher, 22(4), 585-592.

Fast, K. (2010). Captioned video in the listening classroom: Some considerations. Perspectives (TESOL Arabia), 17(1), $8-12$.

Filiz. K. (2009). What makes concept cartoons more effective?Using research to informpractice, Education and Science, 34, 104-118.

Flowerdrew, J., \& Miller, L. (2005). Second language listening: Theory and practice. New York, the USA: Cambridge University Press.

Garza, T. J. (1991). Evaluating the use of captioned video materials in advanced foreign language learning. Foreign Language Annals, 24(3), 239-258.

Grellet, F. (2004). Developing reading skills. Cambridge, the UK: Cambridge University Press.

Hong, Y. N. (2005). The Factors that Influence the Decision Make by Parents with Children Studying at the ElementarySchool when They Choose a Cram School for Their Children- Sampling the Situation of Linyuan. Unpublished master's thesis, National Pingtung University of Education, Pingtung, Taiwan.]

ILTEA Education Group (2012). Retrieved from 2012 May http://www.iltea.org.tw/test/yle_exam.htm\#01

King, J. (2002). Using DVD feature films in the EFL classroom. Computer Assisted Language Learning, 15(5), 509523.

Lee, S. C. (2009) • The Effects of Feature Films upon Listening Comprehension and Speaking Skills: The Case of STUT Applied English Students. Unpublished master's thesis, Southern Tainan University of Tainan, Tainan, Taiwan.

Lee, W. (2009). Making English lessons engaging through video materials supported with Advance organizers and prediction activities. TESL Reporter, 42(2), 57-74. Retrieved from Education Research Complete database.

Leung, Y., \& Jenks M. (2005). Issues in English language teaching: Pedagogy and learning. Taipei, Taiwan: Crane Publishing Company Ltd.

Luo, J. J. (2003). Using DVD films to enhance college freshmen's English listening comprehension and motivation.Electronic Theses and Dissertation System.

MacGillivray, I. K. (2005). Using cartoons to teach students about stereotypes and discrimination: One teacher's lessons from South Park. Journal of Curriculum \& Pedagogy, 2(1), 133-147. Education Research Complete database.

MacMilliam, I. (1984). Video and language comprehension. ELT Journal 40(2), 131-135. 
McArthur, T. (1989). A Foundation Course for Language Teachers. Cambridge: Cambridge University Press.

Norman, D., Levihn, U., \&Hedenquist, J., N. (2002). Communicative ideas. Boston, the USA: Heinie, Thomson.

Peacock, M. (1997). The effects of authentic materials on the motivation of EFL learners. ELT Journal, 51(2), 144-155.

Richards, J. C., Platt, J., \& Platt, H. (1998). Longman dictionary of language teaching \& applied linguistics (EnglishChinese edition). Hong Kong: Addison Wesley Longman China Ltd.

Riddell, D. (2001). Teaching English as a foreign/ second language. London, the UK: Hodder HeadlinePlc.

Stempleski, S. (1987). Short Takes: Using Authentic Video in the English Class. Retrieved from ERIC database.

Stempleski, S. \& Tomalin B. (1990).Video in Action: recipes for using video in language teaching. The UK: CambridgeUniversity Press.

Tsai, C.-C., \&Kuo, P.-C. (2008). Cram school students' conceptions of learning and learning science in Taiwan. International Journal of Science Education, 30(3), 351-373. doi:10.1080/09500690701191425.

Widdowson, H. G. (1996). Comment: Authenticity and autonomy in ELT. ELT Journal, 50(1), 67-68.

Yang, H.-M. G. (1996). Cream schools in Taiwan: Supplementing education. The Educational Forum, 60(1), 64-67.

Zhuang, X. J. (2007). The Influence of Infusing English Cartoon Movie into Teaching on Elementary School Children's English Achievement and Motivation. Unpublished master's thesis, National Tainan University of Tainan, Tainan, Taiwan.

\section{Appendix A}

\section{Worksheet example I}

Name :

Score :

A. Vocabulary

1. promise v. 保證

2. capture V. 獵取; 捕捉

3. monster n. 怪物

4. Mount Everest n. 聖母峰

5. adventure v. 冒險

6. waterfall n. 瀑布

7. alive adj. 活著的

8. beast n. 野獸

9. explorer n. 冒險家

10. goggles n. 蛙鏡

11. human being n. 人類

12. Paradise Falls n. 天堂瀑布

B. Sentences

1. Go on!

2. What's wrong?

C. Please write down three names that you hear in the movie.

D. Write down three things that you can see in Mr. Fredrickson's house.

E. Multiple choices

1. What is the little boy wearing on his face?
a) a mask
b) a hat
c) a pair of goggles

2. What color is the balloon in the little boy's hand?
a) red
b) pink
c) blue
d) yellow

3. The little girl's book is called
a) My Life Book
b) My Adventure Book
c) My Secret Book

Worksheet example II

Up - Part two Name :

Vocabulary $40 \%$ :

1. South America 南美洲

2. thought 想

Score :

(Please write the full sentence down.) 
3. dead 死的 :

4. GPS (Global Positioning System)全球位置測定系統

5. exactly 正確地

6. planet 星球

7. steer 駕駛 ; 带領

8. lost 迷路:

9. assist 幫助; 協助

10. hoist 舉起; 吊起 :

11. snipe【鳥】沙錐,鵚

12. track 足跡

13. collar 項圈 :

Phrases $30 \%$

Write down the meaning and circle the person who said the sentences.

1. There it is.

2. Don't worry. ( Russell / Mr. Fredrickson)

3. Pull back! ( Russell / Mr. Fredrickson)

4. We made it. ( Russell / Mr. Fredrickson)

5. My knee hurts ( Russell / Mr. Fredrickson)

6. Don't be afraid, little snipe. ( Russell / Mr. Frederickson)

Multiple-choice $20 \%$ - Circle the correct answers.

1. How many dogs are chasing the giant bird in the beginning(一開始)?
a. One b. Two
c. Three

2. What name did Russell give to the giant bird?

a. Kevin b. Ken c. Kenny

3. What did the giant bird like to eat?

a. bread b. cookies c. chocolate

4. Can the dogs in the movie talk?
a. Yes
b. No

Q \& A $10 \%$

1. What does “Cross your heart!" mean?

2. Do you like Russell? 